\title{
DETERMINAN PERILAKU KEPATUHAN PAJAK PADA PROFESI DOKTER
}

\author{
Penulis \\ Lalu Hakiki ${ }^{1}$ \\ laloohaqiqee@gmail.com \\ Taufik Raharjo ${ }^{2}$ \\ taufik.raharjo@pknstan.ac.id
}

\begin{abstract}
This study aims to analyze the factors that influence the behavior of doctor's tax compliance with the approach to compliance behavior models. This study was conducted in Indonesia. Data collection in this research is using questionnaire where respondent in this research is doctors who served in several regions in Indonesia. The sampling technique used in this study is convenience sampling methoded. The number of research samples taken as many as 109 respondents. This research uses Partial Least Square (PLS) analysis technique. The results of this study indicate that the variables that have the greatest influence on the behavior of doktor compliance are intention, attitude, and taxpayer identity variables.
\end{abstract}

Keywords: compliance behavior models, tax compliance, intention, attitude, taxpayer identity.

\section{PENDAHULUAN}

Penerimaan pajak merupakan sumber penerimaan negara yang terbesar dalam Anggaran Penerimaan dan Belanja Negara (APBN) dengan porsi lebih dari 70\%. Beberapa tahun terakhir, realisasi penerimaan pajak tidak pernah mencapai target yang ditetapkan. Salah satu upaya yang dapat dilakukan oleh Direktorat Jenderal Pajak (DJP) adalah dengan mengusahakan peningkatan kepatuhan Wajib Pajak (WP). Selama ini rasio kepatuhan WP masih menunjukkan tingkat capaian yang rendah.

Menurut data dari Kementerian Keuangan menyatakan bahwa jumlah WP yang terdaftar sampai dengan tahun 2016 adalah sebanyak 32,77 juta dengan jumlah WP wajib lapor SPT PPh Tahunan sebanyak 20,17 juta. Namun, realisasi SPT PPh Tahunan yang diterima oleh kantor pajak hanya 12,74 juta WP. Rasio kepatuhan penyampaian SPT PPh Tahunan pada tahun 2016 hanya mencapai 63,16\% di mana tingkat rasio kepatuhan yang ditargetkan adalah sebesar 72,50\%. Masih diperlukan upaya yang lebih besar lagi dari DJP untuk meningkatkan kepatuhan penyampaian SPT PPh Tahunan tersebut.

Salah satu upaya yang dilakukan DJP untuk meningkatkan kepatuhan adalah dengan menetapkan rencana dan strategi pemeriksaan. Dalam rencana dan strategi pemeriksaan tersebut ditetapkan kategori-kategori WP yang akan mendapatkan perhatian khusus. Salah satu kategori WP yang mendapat perhatian khusus adalah WP dari kalangan profesional dan WP dengan penghasilan menengah ke atas. Hal ini dapat dilihat dari strategi pemeriksaan DJP beberapa tahun lalu yang tertuang dalam Surat Edaran Direktur Jenderal Pajak Nomor:

\footnotetext{
${ }_{1}^{1}$ Alumni Jurusan Akuntansi Politeknik Keuangan Negara STAN

2 Dosen Jurusan Manajemen Keuangan Politeknik Keuangan Negara STAN
} 
SE-09/PJ/2015 yang mencantumkan WP dari kalangan profesional dalam daftar fokus pemeriksaan DJP untuk kategori WP Orang Pribadi. Salah satu profesi yang memiliki potensi cukup besar dan memungkinkan penghasilan dari banyak sumber adalah profesi dokter. Direktorat Penyuluhan Pelayanan dan Humas DJP dalam artikel Perhitungan Pajak Penghasilan (PPh) Bagi Dokter menjelaskan bahwa dokter karena keahliannya atau kegiatannya dapat memiliki enam kategori sumber penghasilan. Pertama, gaji dan tunjangan serta pembayaran lainnya terkait dengan gaji sebagai pegawai tetap. Kedua, honorarium, komisi, atau fee sebagai tenaga ahli. Ketiga, uang saku, uang presentasi, uang rapat karena dokter sebagai peserta kegiatan. Keempat, hadiah atau penghargaan, bonus, gratifikasi atau imbalan dalam bentuk lain, karena sebagai dokter yang memberikan keuntungan bagi produsen obat-obatan atau alat kesehatan lainnya. Kelima, laba usaha karena sebagai dokter yang buka praktek. Keenam, penghasilan lain yang diterima di luar pekerjaan yang terkait dengan kedokterannya, seperti penghasilan dari bunga deposito, penjualan tanah, hadiah, dividen, dan lain-lain. Banyaknya potensi sumber penghasilan tersebut menyebabkan DJP perlu memberikan pengawasan yang lebih agar negara tidak dirugikan akibat adanya penghasilan yang disembunyikan atau tidak dilaporkan.

Berkaitan dengan hal tersebut, diberitakan dari media Konfrontasi (2016) bahwa komisi yang diterima dokter dari penjualan produk perusahaan farmasi sering tidak dicatatkan dalam laporan pajak, sehingga negara dirugikan karena pajak atas penghasilan tersebut tidak dibayarkan. Hal ini terjadi karena komisi itu sering disamarkan dalam bentuk sponsorship seminar ke luar negeri atau pemberian natura lain. Praktik tersebut mendorong DJP untuk lebih intensif meningkatkan kepatuhan wajib pajak orang pribadi profesi dokter.

Terkait dengan kepatuhan penyampaian SPT Tahunan, dalam beberapa tahun terakhir, data dari Direktorat Potensi, Kepatuhan, dan Penerimaan DJP menunujukkan tingkat kepatuhan penyampaian SPT WP orang pribadi profesi dokter masih sangat rendah. Untuk meningkatkan kepatuhan WP tersebut, DJP perlu mempelajari faktor-faktor apa saja yang dapat membuat WP melaksanakan kewajiban perpajakannya. Dengan mengetahui faktorfaktor tersebut, DJP kemudian dapat menyusun strategi yang lebih tepat untuk mendekati WP.

Faktor-faktor yang mempengaruhi perilaku kepatuhan pajak dapat diprediksi dengan menerapkan beberapa pendekatan. Salah satunya adalah dengan pendekatan Theory of Planned Behavior (TPB) (Langham, 2012) yang merupakan sebuah teori di bidang psikologi untuk mempelajari dan memprediksi perilaku manusia. Dengan menambahkan beberapa variabel penelitian, teori ini dikembangkan menjadi Compliance Behaviour Model (CBM). Faktor lain yang dapat mempengaruhi perilaku kepatuhan pajak adalah adanya sanksi atas ketidakpatuhan yang dilakukan oleh WP. Marta (2013) memaparkan beberapa faktor yang mempengaruhi perilaku kepatuhan, salah satunya adalah compliance and penalties regime 
yang diukur sesuai dengan pendekatan deterrence theory. Variabel lain yang juga dibawakan dalam penelitian tersebut adalah variabel tax system.

\section{Rumusan Masalah Penelitian}

Penelitian ini dilakukan untuk membahas masalah-masalah mengenai faktor-faktor yang dapat mempengaruhi Kepatuhan WP orang pribadi khusus WP yang berprofesi sebagai dokter dalam melaksanakan kewajiban perpajakannya. Permasalahan pada penelitian ini dapat dirumuskan dalam bentuk pertanyaan penelitian sebagai berikut:

1. Bagaimanakah pengaruh attitude terhadap intention?

2. Bagaimanakah pengaruh subjective norms terhadap intention?

3. Bagaimanakah pengaruh perceived behavioural control terhadap intention?

4. Bagaimanakah pengaruh perception cooperation of tax office terhadap intention?

5. Bagaimanakah pengaruh taxpayer's identity terhadap intention?

6. Bagaimanakah pengaruh intention terhadap compliance behaviour?

7. Bagaimanakah pengaruh awareness terhadap compliance behaviour?

8. Bagaimanakah pengaruh tax system terhadap compliance behaviour?

9. Bagaimanakah pengaruh compliance and penalties regime terhadap compliance behaviour?

\section{Tujuan Penelitian}

Tujuan yang ingin dicapai peneliti dalam penyusunan penelitian ini adalah sebagai berikut:

1. Untuk mengetahui pengaruh attitude terhadap intention.

2. Untuk mengetahui pengaruh subjective norms terhadap intention.

3. Untuk mengetahui pengaruh perceived behavioural control terhadap intention.

4. Untuk mengetahui pengaruh perception cooperation of tax office terhadap intention.

5. Untuk mengetahui pengaruh taxpayer's identity terhadap intention.

6. Untuk mengetahui pengaruh intention terhadap compliance behaviour.

7. Untuk mengetahui pengaruh awareness terhadap compliance behaviour.

8. Untuk mengetahui pengaruh tax system terhadap compliance behaviour.

9. Untuk mengetahui pengaruh compliance and penalties regime terhadap compliance behaviour.

\section{Manfaat Penelitian}

Penelitian ini diharapkan dapat memberikan manfaat kepada berbagai pihak sebagai berikut: 
1. Bagi peneliti, hasil penelitian ini dapat dijadikan sebagai bahan untuk memperdalam ilmu tentang perilaku kepatuhan WP dan strategi-strategi untuk meningkatkan kepatuhan WP.

2. Bagi Direktorat Jenderal Pajak, hasil penelitian ini dapat dijadikan sebagai masukan mengenai perilaku kepatuhan WP dan strategi-strategi untuk meningkatkan kepatuhan WP khususnya yang berprofesi sebagai dokter demi tercapainya target penerimaan pajak.

3. Bagi peneliti selanjutnya, penelitian dapat dijadikan sebagai tambahan sumber literatur untuk penelitian-penelitian selanjutnya yang menganalisis mengenai perilaku kepatuhan WP.

\section{LANDASAN TEORI}

\section{Theory of Planned Behavior (TPB)}

Teori ini dikembangan oleh Icek Ajzen yang berasal dari Theory of Reason Action (TRA) yang dikemukakan oleh Fishbein dan Ajzen pada tahun 1975. Teori ini merupakan sebuah teori yang disusun untuk memprediksi dan menjelaskan perilaku manusia dalam konteks yang spesifik. Seperti halnya teori aslinya, yaitu TRA, faktor utama di dalam TPB ini adalah intention atau niat seseorang untuk melaksanakan sebuah tindakan. TRA menyatakan bahwa seseorang mengadopsi atau mengambil kegiatan perilaku tertentu didasarkan pada variabel utama attitude dan subjective norms. Dua variabel tersebut terlihat memiliki pengaruh positif yang mendorong individu melakukan tindakan yang sebenarnya. TPB memperluas kerangka teoritis dalam TRA dan menambahkan faktor perceived behavioral control. Sehingga faktor yang mempengaruhi intention terdiri dari tiga faktor yaitu attitude, subjective norms, dan perceived behavioral control. Intention merupakan indikasi kesiapan individu untuk melakukan perilaku tertentu dan dianggap anteseden langsung dari perilaku. Makin besar intention maka akan makin besar pula kemungkinan sebuah perilaku akan terlaksana. Attitude adalah evaluasi positif dan negatif dari individu atas kinerja suatu perilaku tertentu. Konsepnya adalah sejauh mana perilaku tersebut dinilai positif atau negatif dan sejauh mana keuntungan maupun kerugian atas perilaku tersebut. Subjective norms merupakan persepsi individual mengenai perilaku tertentu yang dipengaruhi oleh penilaian orang lain yang signifikan seperti orang tua, guru, pasangan, dan teman. Penilaian tersebut menurut Sutton (2003) dapat berupa "approve" maupun "disapprove". Dalam konteks perpajakan, subjective norms menggambarkan motivasi untuk mengonfirmasikan dengan orang-orang yang menurutnya penting untuk memutuskan apakah akan patuh melaksanakan kewajiban perpajakan atau tidak (Saad, 2009). Dalam konteks perpajakan, subjective norms menggambarkan motivasi untuk mengonfirmasikan dengan orang-orang yang menurutnya penting untuk memutuskan apakah akan patuh melaksanakan kewajiban perpajakan atau tidak. Selanjutnya Perceived behavioral control mengacu pada persepsi seseorang tentang kemudahan atau kesulitan untuk melakukan suatu tingkah laku. Persepsi ini merupakan 
refleksi dari pengalaman masa lampau individu dan juga halangan atau rintangan untuk menampilkan tingkah laku.

\section{Compliance Behaviour Model (CBM)}

Compliance Behavior Model merupakan model penelitian yang dikembangkan oleh Langham (2012). Model ini berasal dari TPB oleh Ajzen \& Fishbein dengan penambahan tiga variabel lain. Ketiga variabel tersebut yaitu: taxpayer identity, perceived cooperation of tax office, dan awareness of the tax reporting rules and requirements.

\section{Deterrence Theory}

Teori ini dicetuskan pertama kali oleh Becker (1968) berdasarkan pada tindakan rasional manusia. Dalam penelitiannya Becker menyebutkan bahwa tindakan kriminal dapat dicegah dengan meningkatkan kemungkinan si pelaku untuk ditangkap dan diberikan hukuman. Deterrence theory menyatakan bahwa seseorang akan berlaku rasional dan secara tidak langsung akan memilih jalan yang akan memberikan manfaat terbaik bagi dirinya. Terkait dengan kepatuhan perpajakan, perilaku WP dapat dipengaruhi oleh penegakan hukum yang dilakukan oleh DJP. Ketika WP mengetahui bagaimana hukuman yang diberikan kepada WP yang tidak patuh, maka akan menimbulkan rasa takut pada diri WP yang kemudian menyebabkannya untuk berfikir lebih lanjut jika berniat untuk tidak melakukan kewajiban perpajakannya.

\section{PENELITIAN TERDAHULU DAN PENGAMBANGAN HIPOTESIS}

Penelitian Saad (2010) mencari tahu peran keadilan pajak dalam menentukan kepatuhan pajak di Malaysia. Hasil penelitian Saad (2010) menjelaskan bahwa (a). Fairness perception of taxpayer bersifat multidimensional, yang terdiri dari: general fairness, exchange fairness, horizontal fairness, vertical fairness, retributive fairness dan administration fairness; (b). Fairness perception of taxpayer tidak berpengaruh terhadap intention WP untuk mematuhi kewajiban perpajakan; (c). Tax knowledge berpengaruh positif terhadap fairness perception of taxpayer; (d). Taxpayer's attitude dan subective norms berpengaruh positif terhadap intention WP untuk mematuhi kewajiban perpajakan; (e). Perceived behavioural control tidak berpengaruh terhadap intention Pajak untuk mematuhi kewajiban perpajakan; (f). Fairness perception of taxpayer tidak berpengaruh terhadap taxpayer's attitude; (g). Tax knowledge dan tax complexity tidak berpengaruh terhadap perceived behavioural control.

Langham (2012) menarik kesimpulan bahwa tidak ada solusi sederhana untuk menghilangkan ketidakpatuhan. Kantor pajak harus terus-menerus memastikan bahwa WP diberi kesempatan yang adil untuk patuh pajak dan mendapatkan kesamaan dalam kompleksitas hukum dan membuat semua warga Australia mampu dan mau bertanggung jawab sesuai dengan sistem pajak mereka. Penelitian menjelskan baahwa (a). taxpayer attitude berpengaruh positif dan signifikan terhadap intention to comply; (b). subjective norms 
berpengaruh positif dan signifikan terhadap intention to comply; (c). perceived behavioural control tidak berpengaruh signifikan terhadap intention to comply; (d). perception cooperation of tax office tidak berpengaruh signifikan terhadap intention to comply; (e). taxpayer's identity tidak berpengaruh signifikan terhadap intention to comply; (f). intention to comply berpengaruh positif dan signifikan terhadap compliance behavior; (g). awareness berpengaruh positif dan signifikan terhadap compliance behavior; (h). perception cooperation of tax office berpengaruh positif dan signifikan terhadap compliance behavior; (i). taxpayer identity tidak berpengaruh signifikan terhadap compliance behaviour.

Dalam penelitian Smart (2013) menggunakan kerangka dasar TPB sebagai dasar penelitiannya dengan menambahkan beberapa variabel yang relevan antara lain variabel compliance and penalties regime dan tax system. Hasil penelitiannya secara ringkas adalah bahwa faktor-faktor non ekonomis seperti attitudes dan keyakinan pada diri merupakan faktor yang sangat baik untuk memprediksi perilaku kepatuhan perpajakan. Selain itu, simpulan yang didapat adalah bahwa sanksi informal yang berbentuk moral dan perasaan lebih efektif dibandingkan dengan sanksi hukum secara formal

Hipotesis yang diajukan pada penelitian ini adalah berdasarkan pada teori CBM yang menyatakan bahwa attitude, subjective norms, perceived behavioural control, perception cooperation of tax office, dan taxpayer's identity mempengaruhi intention, yang kemudian intention ini bersama dengan awareness mempengaruhi compliance behaviour. Selain itu, tax system dan compliance and penalties regime juga turut mempengaruhi compliance behaviour. Dari teori-teori tersebut, maka dapat diajukan hipotesis sebagai berikut:

$\mathrm{H} 1$ : Attitude berpengaruh positif dan signifikan terhadap intention.

$\mathrm{H} 2$ : Subjective norms berpengaruh positif dan signifikan terhadap intention.

H3 : Perceived behavioural control berpengaruh positif dan signifikan terhadap intention.

H4 : Perception cooperation of tax office berpengaruh positif dan signifikan terhadap intention.

H5 : Taxpayer's identity berpengaruh positif dan signifikan terhadap intention.

H6 : Intention berpengaruh positif dan signifikan terhadap compliance behaviour.

H7 : Awareness berpengaruh positif dan signifikan terhadap compliance behaviour.

H8 : Tax system berpengaruh positif dan signifikan terhadap compliance behaviour.

H9 : Compliance and penalties regime berpengaruh positif dan signifikan terhadap compliance behaviour.

\section{METODE PENELITIAN}




\section{Jenis Data dan Metode Pengumpulan Data}

Penelitian ini menggunakan data promer yang bersumber kuesioner yang diisi oleh WP orang pribadi profesi dokter di Indonesia. Kuesioner tersebut menggunakan skala Likert 7 poin. Penyebaran kuesioner dilakukan dengan bantuan media sosial dalam bentuk tautan google form di mana responden akan menjawab pertanyaan kuesioner tersebut secara online.

\section{Populasi dan Sampel}

Populasi responden dalam penelitian ini adalah seluruh dokter di Indonesia. Berdasarkan data dari Konsil Kedokteran Indonesia, jumlah dokter/dokter gigi seluruh Indonesia per tanggal 31 Mei 2017 adalah sebanyak 184.489 dokter, dengan rincian dokter sebanyak 118.754 , dokter gigi sebanyak 28.894 , dokter spesialis sebanyak 33.537 , dan dokter gigi spesialis sebanyak 3.304.

Metode pengambilan sampel yang digunakan dalam penelitian ini adalah pemilihan sampel secara nonprobabilitas yaitu convenience sampling. Convenience sampling merupakan metode pengambilan sampel yang dilakukan dengan memilih sampel secara bebas dan tanpa ada persyaratan khusus. Metode ini digunakan karena memudahkan dalam pengambilan data penelitian. Untuk mempercepat penyebaran dipergunakan pula snowball sampling di mana responden yang menerima kuesioner dapat menyebarkan lagi ke rekanrekan sesama dokter yang memenuhi kriteria. Ukuran sampel ditentukan dengan menggunakan rumus Slovin dengan batas toleransi kesalahan $10 \%$, maka jumlah sampel yang didapatkan adalah 99,94, atau sebanyak 100 orang dokter.

\section{Variabel Penelitian}

Variabel yang digunakan dalam penelitian ini terutama berpedoman pada variabelvariabel pada Compliance Behaviour Model yaitu sebagai berikut:

Variabel Attitude terdiri dari affective attitude dan instrumental attitude. Affective attitude menunjukkan apa yang dirasakan seseorang jika melakukan sesuatu, misalnya perasaan senang atau tidak senang, kecewa, sedih, dan lain-lain. Instrumental attitude menunjukkan keuntungan atau manfaat yang didapat seseorang jika melakukan sesuatu. Indikator-indikator variabel ini antara lain WP merasa senang dan tidak mersa kecewa jika melaporkan pajak dengan benar.

Variabel Subjective Norm berkaitan dengan motivasi seseorang untuk melakukan tindakan berdasarkan pengaruh dari orang-orang di sekitarnya.

Variabel Perceived Behavioural Control menunjukkan kontrol perilaku yang dirasakan oleh WP dan juga fasilitas-fasilitas atau kemudahan-kemudahan serta kesulitan dalam melaporkan SPT dengan benar. 
Variabel Taxpayer Identity menunjukkan bagaimana WP menilai dirinya atau menunjukkan karakter yang dimiliki oleh WP misalnya kejujuran, kecerdasan, kemurahan hati dan pemikiran mereka.

Variabel Perceived Cooperation of Tax Office menunjukkan tingkat kepercayaan dan penilaian WP terhadap pegawai pajak dalam membantu mereka dalam melaksanakan kewajiban pajak.

Variabel Awareness menunjukkan kesadaran dan pengetahuan WP mengenai sistem dan peraturan perpajakan yang berlaku.

Variabel Intention mengandung unsur-unsur kemauan, harapan, niat dan keinginan untuk melakukan perilaku tertentu.

Variabel Tax System menggambarkan bagaimana seseorang memandang sistem perpajakan yang berlaku. Sistem perpajakan yang rumit, banyaknya formulir, dan aturan cenderung membuat seseorang mengurungkan niatannya untuk menjadi patuh.

Variabel Compliance and Penalties Regime menggambarkan bagaimana persepsi seseorang mengenai penegakan hukum yang sedang berlangsung.

Variabel Compliance Behaviour mengacu pada perilaku nyata yang dilakukan WP dalam melaksanakan kewajiban perpajakannya.

\section{Model penelitian}

Berdasarkan hipotesis yang telah dibangun dalam landasan teori dan variabelvariabel yang telah disebutkan dalam bagian sebelumnya, model penelitian yang akan digunakan pada penelietian ini dapat diilustrasikan dengan Gambar 1. Model tersebut menggambarkan adanya pengaruh antar variabel, baik pengaruh langsung maupun pengaruh tidak langsung.

Gambar 1. Model Penelitian

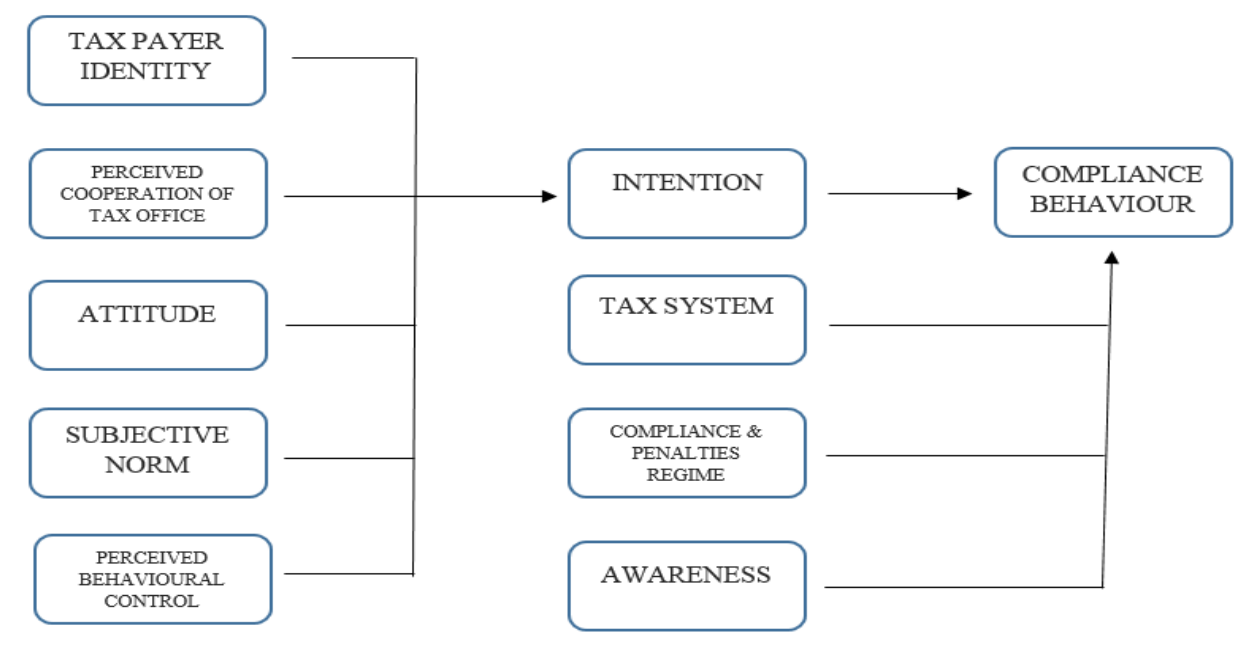




\section{Pengujian Hipotesis}

Analisis data dalam penelitian ini menggunakan pendekatan Structural Equation Model (SEM) dengan metode Partial Least Square (PLS). Alat bantu analisis yang digunakan adalah aplikasi SmartPLS 3.2.6 32 bit.

\section{HASIL DAN PEMBAHASAN}

\section{Pelaksanaan Penelitian}

Data yang digunakan dalam penelitian ini adalah data dari hasil kuesioner. Penyebaran kuesioner dilakukan mulai dari tanggal 1 Mei 2017 hingga 14 Juni 2017. Total kuesioner yang berhasil dikumpulkan adalah sebanyak 109 data kuesioner. Seluruh data kuesioner tersebut digunakan untuk diolah lebih lanjut dalam penelitian.

\section{Profil Responden}

Responden dalam penelitian ini adalah 28 responden laki-laki dan 81 responden perempuan. Berdasarkan usia, didapatkan 54,13\% responden berusia usia 21-30 tahun, $41,28 \%$ berusia 31-40 tahun, dan 4,59\%. responden berusia di atas 40 tahun.

Responden dengan pendidikan terakhir profesi dokter umum adalah $74,31 \%$, profesi dokter gigi sebanyak $14,68 \%$, profesi dokter spesialis $5,50 \%$, dan lulusan pascasarjana yaitu S-2 sebanyak 5,50\%. Adapun untuk responden dengan pendidikan terakhir profesi dokter gigi spesialis dan S3 tidak didapatkan pada penelitian ini.

Data mengenai domisili responden didapatkan responden yang berasal dari wilayah Pulau Jawa memiliki jumlah yang paling banyak yaitu 64 responden atau 58,72\% dari jumlah seluruh responden, diikuti oleh responden yang berasal dari Pulau Sumatera sebanyak 18,35\%, hingga responden dari wilayah Papua dan Maluku dengan jumlah responden paling sedikit yaitu $2,75 \%$. Pembagian wilayah responden ini dimaksudkan agar data yang digunakan lebih representatif sehingga dapat mewakili seluruh dokter yang tersebar di seluruh wilayah Indonesia sesuai dengan proporsi persebarannya menurut data dari Konsil Kedokteran Indonesia.

\section{Evaluasi Outer Model}

Berdasarkan Rule of Thumb for Model Evaluation menurut Hair (2011) dalam pengujian outer mode/ meliputi pengujian validitas dan reliabilitas. Pengujian validitas meliputi convergent validity dan discriminant validity. Setelah itu diuji reliabilitasnya dengan menggunakan nilai loading dan composite reliability. Uji validitas dan realibilitas tersebut menggunakan prosedur kalkulasi dengan PLS Algorithm dan Bootstrapping pada SmartPLS. 


\section{Convergent Validity}

Tahapan convergent validity berfungsi untuk menguji seberapa besar hubungan antara konstruk dan indikator. Pada pengujian pertama, seluruh indikator pada seluruh konstruk pada model akan disertakan. Kemudian dari hasil pengujian tersebut dievaluasi melalui nilai loading dari tiap-tiap indikator. Pertama-tama, langkah yang dilakukan adalah menghitung nilai loading. Besar nilai loading yang ideal adalah 0,7 ke atas, yang menandakan bahwa terdapat lebih banyak shared variance antara konstruk dan indikator dibandingkan error variance. Namun demikian untuk penelitian tahap awal dari pengembangan skala pengukuran, nilai loading 0,5 masih dianggap cukup. Indikator yang memiliki nilai loading 0,5 tetap dipertahankan selama memiliki $t$-values yang signifikan, yaitu di atas 1,65 pada tingkat signifikansi 10\%. Namun indikator dengan nilai loading 0,5 dan 0,6 harus diperhatikan apakah lolos kriteria dalam cross loading dan Fornell-Larcker Criterion (Square-root of AVE) pada tahap uji discriminant validity. Jika indikator tersebut tidak lolos, maka dihapus dari model penelitian. Dari hasil uji outer model atas kesepuluh variabel di atas, maka semua indikator diikutsertakan dalam perhitungan, tidak ada yang dibuang.

Selain dengan memperhitungkan nilai loading tiap indikator dan nilai T Statistic, dalam pengujian convergent validity juga dilakukan penghitungan nilai Average Variance Extracted (AVE) untuk membuktikan bahwa indikator memiliki nilai varians atau keberagaman yang lebih besar terhadap konstruknya dibandingkan dengan konstruk lain di dalam model. Nilai AVE yang diharapkan adalah lebih besar dari 0,5 (Hair, 2011). Nilai AVE lebih besar dari 0,5 menandakan bahwa indikator tersebut memiliki nilai varian yang besar pada konstruknya. Nilai AVE yang didapat dari uji dalam penelitian ini mempunya nilai lebih dari 0,5 pada setiap konstruk.

\section{discriminant validity}

Cara yang dapat dilakukan untuk menentukan discriminant validity adalah dengan melihat nilai akar kuadrat Average Variance Extracted (AVE) atau Square Root of AVE. Nilai AVE dihasilkan melalui prosedur bootstrapping pada SmartPLS. Jika nilai akar kuadrat AVE setiap konstruk lebih besar daripada nilai korelasi antara konstruk dengan konstruk lainnya dalam model, maka dikatakan memiliki nilai discriminant validity yang baik.

Selain dengan melihat nilai akar kuadrat Average Variance Extracted (AVE) atau Square Root of AVE, discriminant validity dapat diuji dengan cross loading. Cross Loading dilakukan dengan cara membandingkan nilai loading antara indikator pada suatu konstruk dengan indikator pada konstruk yang lain. Suatu konstruk dapat disebut memiliki discriminant validity yang memadai apabila nilai loading di indikator pada konstruk tersebut lebih besar dari konstruk lainnya. Setelah dilihat hasil cross loading, terlihat bahwa indikator PBC_2 tidak 
dapat memenuhi kriteria, maka indikator PBC_2 harus dihapus sehingga konstruk perceived behavioural control hanya mempunyai satu indikator tersisa.

Gambar 2 Model Penelitian Revisi

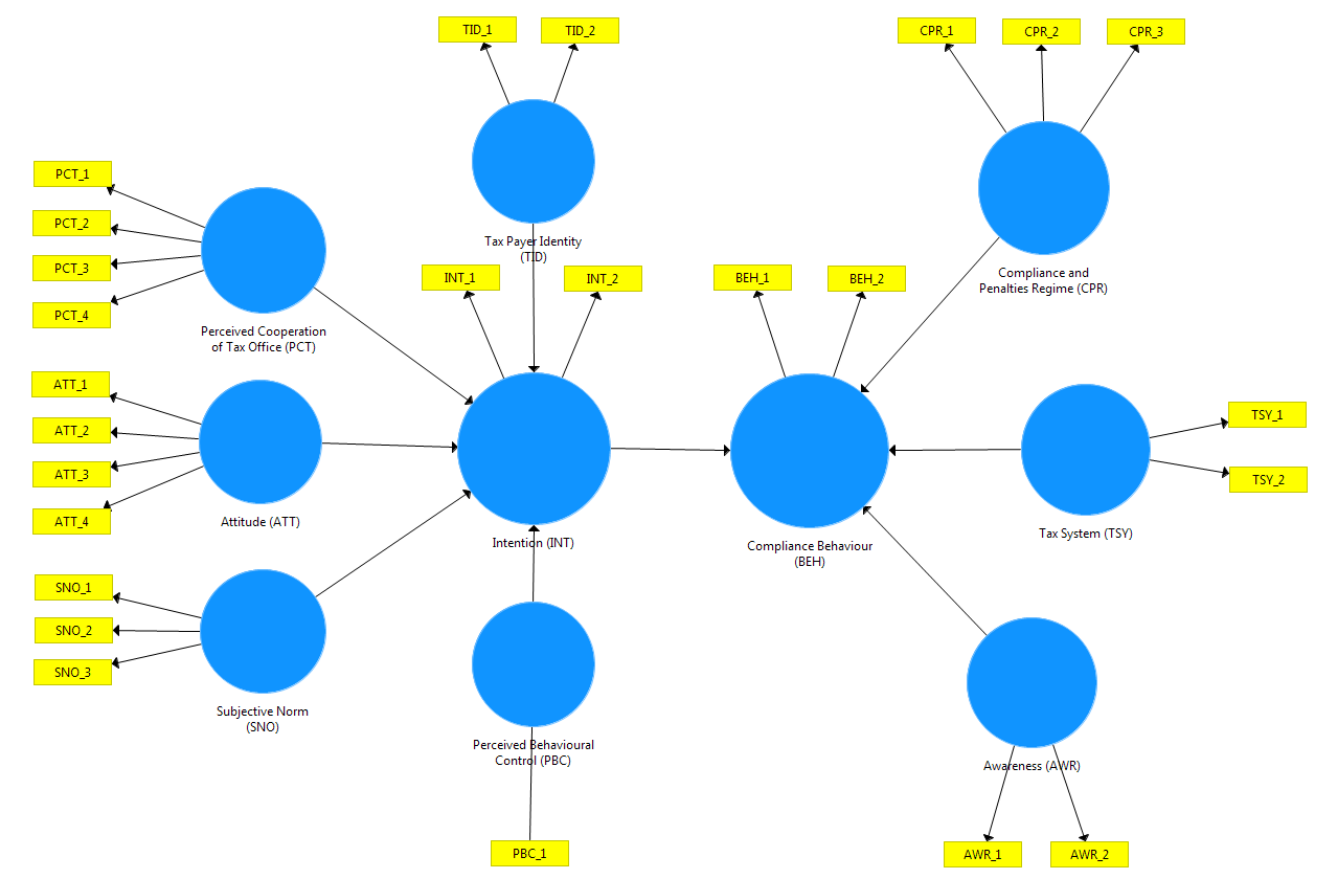

Sumber: Diolah dari data primer dengan SmartPLS 3.2.6

\section{composite reliability}

Composite Reliability dilakukan untuk menguji reliabilitas. Pengujian composite reliability dilakukan dengan menggunakan composite reliability index. Suatu konstruk dikatakan reliabel jika nilai composite reliability di atas 0,60 . Nilai yang didapatkan jauh melebihi angka 0,6. Hasil ini menunjukkan bahwa seluruh konstruk memiliki nilai reliabilitas yang konsisten.

\section{cronbach's alpha}

Uji reliabilitas berikutnya yang dilakukan setelah uji composite reliability dalam penelitian ini adalah pengujian dengan mengukur nilai cronbach's alpha dari masing-masing konstruk. Hasil uji ini menunjukkan bahwa nilai cronbach's alpha yang didapat melebihi 0,7. Hal ini menandakan bahwa tiap konstruk telah memenuhi kriteria cronbach's alpha. Berdasarkan hasil kedua uji reliabilitas ini, seluruh konstruk dalam model penelitian ini telah memenuhi kriteria uji composite reliability dan cronbach's alpha, sehingga dengan demikian konstruk dalam penelitian ini sudah reliabel. 


\section{Evaluasi Inner Model}

Pengujian inner model atau evaluasi model struktural dilakukan untuk menggambarkan pengaruh konstruk independen terhadap konstruk dependen berdasarkan hipotesis yang telah diajukan sebelumnya. Dalam menguji hipotesis dengan menggunakan PLS, cara yang digunakan adalah melihat nilai $R$-Square, nilai koefisien jalur (Path Coefficient) dari inner model, dan nilai signifikansi T-statistic.

\section{R-Square}

Nilai $R$-Square dari variabel endogen intention adalah sebesar 0,702 yang berarti variabel eksogen yang terdiri dari attitude, subjective norm, perceived behavioural control, taxpayer identity, dan perceived cooperation of tax office mampu menjelaskan $70,2 \%$ perubahan pada variabel Intention. Sisanya sebesar $29,8 \%$ dipengaruhi oleh variabel lain diluar variabel yang diteliti dalam penelitian ini. Kemudian nilai R-Square untuk variabel endogen compliance Behaviour memperoleh nilai sebesar 0,520. Hal ini berarti variabel eksogen yang terdiri dari awareness, intention, tax system, dan compliance and penalties regime mampu menjelaskan $52,0 \%$ perubahan pada variabel endogennya yaitu compliance Behaviour. Sisanya sebesar $48,0 \%$ dipengaruhi oleh variabel lain diluar penelitian ini.

\section{Uji Hipotesis}

Untuk menilai signifikansi, digunakan nilai $T$-statistic. Suatu hubungan antar konstruk dianggap signifikan jika nilai $T$-statistic lebih besar dari nilai t tabel. Dalam penelitian ini digunakan significance level sebesar $10 \%$ sehingga nilai t tabel sebesar 1,65. Jika $T$-statistic memiliki nilai di atas 1,65 maka dianggap signifikan.

Gambar 3. Model Hasil PLS Algorithm

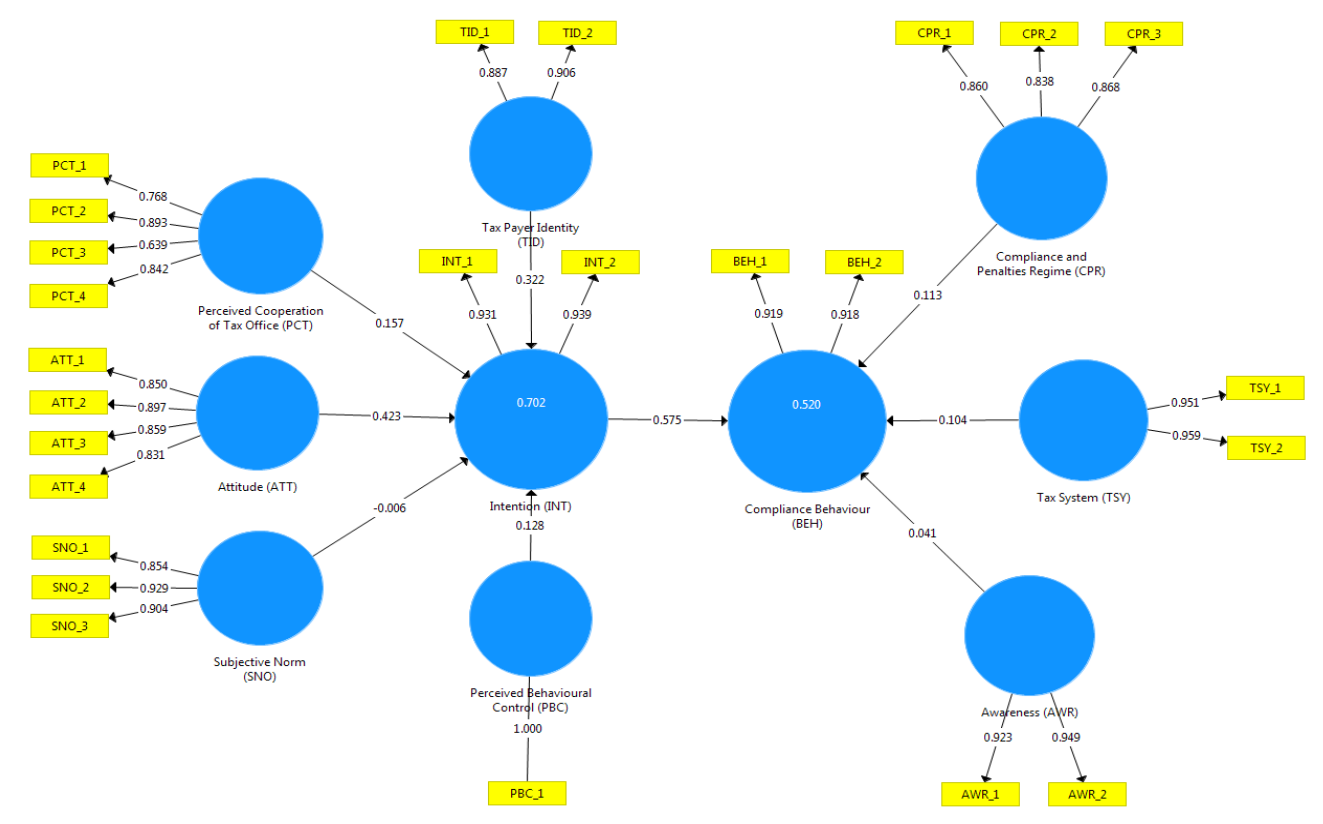


Besaran koefisien jalur atau tingkat pengaruh dari masing-masing variabel terhadap variabel yang dipengaruhinya juga bisa dilihat dari tabel 1. Pada tabel tersebut tertera koefisien pengaruh antar variabel, baik pengaruh langsung (direct effect) maupun pengaruh tidak langsung (indirect effect). Pengaruh yang termasuk dalam kategori langsung adalah pengaruh dari variabel-variabel attitude, subjective norm, perceived behavioural control, taxpayer identity, dan perceived cooperation of tax office terhadap variabel intention. Selain itu, yang juga termasuk dalam kategori pengaruh langsung adalah pengaruh dari variabelvariabel intention, awareness, tax system, dan compliance and penalties regime terhadap variabel compliance behaviour. Adapun yang termasuk dalam kategori pengaruh tidak langsung adalah pengaruh dari variabel-variabel attitude, subjective norm, perceived behavioural control, taxpayer identity, dan perceived cooperation of tax office terhadap variabel compliance behaviour.

Tabel 1. Pengaruh Total antar Variabel

\begin{tabular}{|l|l|l|l|l|l|l|l|l|l|l|}
\hline & ATT & $\begin{array}{c}\text { AW } \\
\text { R }\end{array}$ & BEH & CPR & INT & PBC & PCT & SNO & TID & TSY \\
\hline Attitude (ATT) & & & 0,244 & & 0,423 & & & & & \\
\hline Awareness (AWR) & & & 0,041 & & & & & & & \\
\hline Compliance Behaviour (BEH) & & & & & & & & & & \\
\hline $\begin{array}{l}\text { Compliance and Penalties } \\
\text { Regime (CPR) }\end{array}$ & & & 0,113 & & & & & & & \\
\hline Intention (INT) & & 0,575 & & & & & & & \\
\hline $\begin{array}{l}\text { Perceived Behavioural } \\
\text { Control (PBC) }\end{array}$ & & & 0,073 & & 0,128 & & & & & \\
\hline $\begin{array}{l}\text { Perceived Cooperation of Tax } \\
\text { Office (PCT) }\end{array}$ & & & 0,090 & & 0,157 & & & & & \\
\hline Subjective Norm (SNO) & & & $-0,003$ & & 0,006 & & & & & \\
\hline Tax Payer Identity (TID) & & & 0,185 & & 0,322 & & & & & \\
\hline Tax System (TSY) & & & 0,104 & & & & & & & \\
\hline
\end{tabular}

Sumber: Diolah dari data primer dengan SmartPLS 3.2.6

Dari Tabel 1 dapat kita ketahui bahwa variabel yang memiliki pengaruh paling besar terhadap variabel compliance behaviour adalah variabel intention dengan besar koefisien 0,575 , yang merupakan pengaruh langsung. Setelah variabel intention, variabel yang paling berpengaruh berikutnya terhadap variabel compliance behaviour adalah variabel attitude dengan besar koefisien 0,244, yang merupakan pengaruh tidak langsung. Variabel attitude ini mempengaruhi variabel compliance behaviour melalui variabel intention. Hal ini berarti bahwa perilaku kepatuhan pajak sangat ditentukan oleh niatan atau keinginan dari WP untuk memenuhi kewajiban perpajakannya. Niatan atau keinginan WP ini sangat dipengaruhi oleh perasaan atau emosi yang dirasakan ketika ia memenuhi kewajiban perpajakannya, misalnya perasaan senang, sedih, kecewa, atau perasaan lainnya. Selain perasaan atau emosi, keinginan WP ini juga sangat dipengaruhi oleh ada tidaknya manfaat yang dirasakan ketika 
ia memenuhi kewajiban perpajakannya, misalnya perasaan puas karena merasa telah ikut berkontribusi terhadap penerimaan negara.

\section{Pembahasan}

\section{Attitude Berpengaruh Positif dan Signifikan terhadap Intention}

Hal ini mengindikasikan bahwa apa yang dirasakan oleh wajib pajak dokter dalam melaksanakan kewajiban pajak berpengaruh terhadap tingkat keinginan mereka untuk patuh. Pengaruh positif mengindikasikan bahwa semakin positif attitude wajib pajak dokter dalam memandang pemenuhan kewajiban perpajakannya maka semakin besar keinginan mereka untuk patuh dalam memenuhi kewajiban perpajakannya tersebut. Hasil pengujian ini sejalan dengan hasil penelitian Langham (2012) dan Saad (2010) yang mengungkapkan bahwa taxpayer's attitude berpengaruh positif terhadap taxpayer's intention to comply.

\section{Subjective Norms Tidak Berpengaruh Signifikan terhadap Intention}

Hal ini mengindikasikan bahwa pengaruh dari lingkungan di sekitar Wajib Pajak dokter tidak berpengaruh terhadap niat mereka untuk melaksanakan kewajiban perpajakan. Indikator dari variabel subjective norms terkait dengan pengaruh dari orang-orang terdekat terhadap diri seseorang. Terpengaruh atau tidaknya seseorang bergantung pada kepribadian orang tersebut. Hasil pengujian ini tidak sejalan dengan hasil penelitian Langham (2012) dan Saad (2010) yang mengungkapkan bahwa subjective norms berpengaruh positif terhadap taxpayer's intention to comply.

\section{Perceived Behavioural Control Berpengaruh Positif dan Signifikan terhadap Intention}

Hal ini mengindikasikan bahwa ketika tidak ada kendala dan kesulitan yang dirasakan wajib pajak pada saat menghitung, membayar, dan melaporkan pajaknya, maka keinginannya untuk patuh akan meningkat. Hasil pengujian ini tidak sejalan dengan hasil penelitian Langham (2012) dan Saad (2010) yang mengungkapkan bahwa perceived behavioural control tidak berpengaruh terhadap taxpayer's intention to comply.

\section{Perception Cooperation of Tax Office Berpengaruh Positif dan Signifikan terhadap Intention}

Hal ini menunjukkan bahwa pelayanan pada wajib pajak berpengaruh positif dan signifikan terhadap niatan wajib pajak untuk memenuhi kewajiban perpajakannya. Pengaruh positif ini mengindikasikan bahwa makin baik penilaian wajib pajak terhadap pelayanan petugas pajak, maka makin tinggi pula keinginan wajib pajak untuk patuh. Hasil pengujian ini tidak sejalan dengan hasil penelitian Langham (2012) yang mengungkapkan bahwa perceived cooperation of tax office tidak berpengaruh terhadap taxpayer's intention to comply. 


\section{Taxpayer's Identity Berpengaruh Positif dan Signifikan terhadap Intention}

Hal ini mengindikasikan bahwa pandangan wajib pajak terhadap dirinya sebagai wajib pajak yang baik sangat berpengaruh terhadap niat mereka untuk berperilaku patuh dalam melaksanakan kewajiban perpajakannya. Pengaruh positif menunjukkan bahwa semakin positif Wajib Pajak memandang kepatuhan dirinya maka semakin tinggi keinginannya untuk berperilaku patuh. Hasil penelitian ini tidak sejalan dengan penelitian Langham (2012) yang mengungkapkan bahwa tax payer identity secara parsial tidak berpengaruh terhadap intention to comply.

\section{Intention Berpengaruh Positif dan Signifikan terhadap Compliance Behaviour}

Hal ini mengindikasikan bahwa niat yang muncul dalam diri wajib pajak dokter untuk melaksanakan kewajiban perpajakan berpengaruh terhadap tindakan aktual mereka untuk melaksanakan kewajiban perpajakan. Pengaruh positif mengindikasikan makin tinggi keinginan atau niat untuk melaksanakan kewajiban perpajakan maka akan makin tinggi pula kecenderungan untuk patuh. Hasil pengujian ini sejalan dengan hasil penelitian Langham (2012) yang mengungkapkan bahwa intention of tax payers to comply berpengaruh positif terhadap compliance behaviour.

\section{Awareness Tidak Berpengaruh Signifikan Terhadap Compliance Behaviour}

Hal ini mengindikasikan bahwa tingkat pengetahuan wajib pajak mengenai peraturan perpajakan tidak berpengaruh terhadap perilaku aktual mereka dalam melaksanakan kewajiban perpajakan. Hasil pengujian ini tidak sejalan dengan hasil penelitian Langham (2012) yang mengungkapkan bahwa awareness of the tax reporting rules and requirements berpengaruh positif dan signifikan terhadap compliance behaviour.

\section{Tax System Tidak Berpengaruh Signifikan terhadap Compliance Behaviour}

Hal ini mengindikasikan bahwa kesederhanaan sistem perpajakan dapat mempengaruhi wajib pajak untuk lebih patuh. Namun, kesederhanaan sistem perpajakan tersebut tidak dapat memberikan dampak kepatuhan yang memadai. Hasil pengujian ini tidak sejalan dengan hasil penelitian Smart (2013) yang mengungkapkan bahwa tax system tidak berpengaruh positif terhadap compliance behaviour.

\section{Compliance and Penalties Regime Tidak Berpengaruh Signifikan terhadap Compliance Behaviour}

Hal ini mengindikasikan bahwa penegakan hukum yang dilakukan oleh DJP dengan penerapan sanksi dapat mempengaruhi perilaku wajib pajak untuk patuh, namun pengaruhnya tidak memadai. Hal ini berarti bahwa pemberian sanksi bukan termasuk dalam salah satu faktor utama yang menyebabkan perilaku kepatuhan wajib pajak. Hasil pengujian ini tidak sejalan dengan hasil penelitian Smart (2013) yang mengungkapkan bahwa compliance and penalties regime tidak berpengaruh positif terhadap compliance behaviour. 


\section{SIMPULAN}

Berdasarkan analisis yang telah dilakukan, maka dapat ditarik kesimpulan bahwa variabel yang memiliki pengaruh paling besar terhadap perilaku kepatuhan WP dokter adalah variabel intention, attitude, dan taxpayer identity. Untuk Intention, makin tinggi keinginan WP untuk patuh, makin tinggi pula tingkat perilaku aktual mereka untuk patuh dalam memenuhi kewajiban perpajakannya. Variabel Attitude menggambarkan makin baik/positif perasaan yang dirasakan WP ketika melaksanakan kewajiban perpajakannya, maka makin tinggi keinginan WP untuk patuh. Mengenai Taxpayer's identity, berarti bahwa jika WP memandang dirinya adalah WP yang baik, maka akan meningkatkan niat mereka untuk patuh dalam melaksanakan kewajiban perpajakannya.

\section{KETERBATASAN}

Keterbatasan dalam penelitian ini adalah responden pada penelitian ini belum dapat mewakili semua kalangan dokter. Masih terdapat ketimpangan proporsi jumlah responden dalam hal usia, dan pendidikan responden, sehingga secara kesuluruhan responden pada penelitian ini masih belum cukup representatif.

\section{SARAN}

Dari hasil analisis, intention, attitude, dan taxpayer identity merupakan faktor yang paling signifikan dalam mempengaruhi perilaku kepatuhan wajib pajak. Dengan demikian, pemerintah, dalam hal ini DJP, perlu membuat strategi untuk meningkatkan peran tiga faktor tersebut dengan membangun kedekatan emosional antara DJP dengan dokter-dokter yang tergabung dalam Ikatan Dokter Indonesia (IDI). Strategi yang dapat digunakan yaitu dengan membuat kegiatan-kegiatan sosialisasi perpajakan yang dikemas dengan baik sehingga mampu memberikan pula manfaat bagi para dokter.

\section{DAFTAR PUSTAKA}

Ajzan, Icek.. "The Theory of Planned Behavior". Organizational Behavior Human Decision Processes. 50 (1991): 179-211.

Becker, G.. "Crime and Punishment: An Economic Approach". Journal of Political Economy, 76(2) (1968), 169-217.

Direktorat Jenderal Pajak. Surat Edaran Direktur Jenderal Pajak Nomor SE-09/PJ/2015 Tentang Rencana dan Strategi Pemeriksaan Tahun 2015.

Ghozali, Imam.. Structural Equation Modelling, Metode Alternatif Dengan Partial Least Square. Semarang: Universitas Diponegoro. (2014)

Hair, Joseph F. "PLS-SEM: Indeed a Silver Bullet". Journal of Marketing Theory and Practice, Vol. 19 No. 2 pp (2011). 139-151.

Hair, Joseph F. A Primer on Partial Least Squares Structural Equation Modelling (PLS-SEM). Los Angeles: Sage Publications, Inc. (2014) 
Konfrontasi.http://www.konfrontasi.com/content/ekbis/ditjen-pajak-intensif-tingkatkankepatuhan-wajib-pajak-profesi-dokter (Diakses 31 Mei 2017)

Konsil Kedokteran Indonesia. http://www.kki.go.id/ (Diakses 31 Mei 2017)

Konsil Kedokteran Indonesia. Laporan Tahunan 2015 Konsil Kedokteran Indonesia. http://www.kki.go.id/index.php/subMenu/1158 (Diakses 30 Mei 2017)

Konsultan Statistik. http://www.konsultanstatistik.com/2009/03/structural-equationmodeling_17.html (Diakses 31 Mei 2017)

Langham, Jo'Anne, Neil Paulsen, dan Charmine E.J. Hartel. "Improving Tax Compliance Strategies: Can the Theory of Planned Behaviour predict Business Compliance?" School of Taxation and Business Law (Atax). (2012). Volume 10.

Liputan6. $\quad$ http://bisnis.liputan6.com/read/2842086/sri-mulyani-kepatuhan-bayar-pajakrendah-pengaruhi-apbn (Diakses 31 Mei 2017)

Pemerintah Republik Indonesia. Undang-Undang Nomor 29 Tahun 2004 tentang Praktik Kedokteran.

Pemerintah Republik Indonesia. Undang-Undang Nomor 36 Tahun 2008 tentang Perubahan Keempat atas Undang-Undang Nomor 7 tahun 1983 tentang Pajak Penghasilan.

Pemerintah Republik Indonesia. Undang-Undang Republik Indonesia Nomor 16 Tahun 2009 tentang Perubahan Keempat atas Undang-Undang Nomor 6 Tahun 1983 tentang Ketentuan Umum dan Tata Cara Perpajakan.

Saad, Natrah. Fairness Perception and Compliance Behaviour: The Case of Salaried Taxpayers in Malaysia after Implementation of the Self-Assessment System. (2010)

Sekaran, Uma. Metodologi Penelitian untuk Bisnis: Buku 1. Jakarta: Penerbit Salemba Empat. (2006)

Smart, Martha. Applying the Theory of Planned Behaviour And Structural Equation Modelling To Tax Compliance Behaviour: A New Zealand Study. University of Canterbury. (2013)

Sutton, Stephen, David P. French, Susie J. Hennings, Jo Mitchell, Nicholas J. Wareham, Simon Griffin, Wendy Hardeman, dan Ann Louise Kinmonth.. "Eliciting Salient Beliefs in Research on the Theory of Planned Behaviour: The Effect of Question Wording". Current Psyhology: Developmental, Learning, Personality, Social. Vol 22 (2003): 234251.

Vallerand, Robert J., Luc G.Pelletier, Paul Deshaies, Jean-Pierre Cuerrier, dan Claude Mongeau. 1992. "Ajzen and Fishbeins's Theory of Reasoned Action as Applied to Moral Behavior: A Confirmatory Analysis". Journal of Personality and Social Psychology. Vol.62, No. 1(1992): 98-109. 